\title{
Restricción presupuestaria y desempeño fiscal de Santander de Quilichao- Colombia, 2004-2016
}

\section{Budget constraint and fiscal performance of Santander de Quilichao- Colombia, 2004-2016}

Edwin-Arbey Hernández-García; Mayra-Alejandra Zapata-Prado²; Sergio-Leonardo González-Tique ${ }^{3}$; Andrés-Aníbal Armas-Moyano ${ }^{4}$

Artículo de investigación:

Fecha de recepción: 2019/12/01

Fecha de aceptación: 2019/12/16

Esta publicación se encuentra bajo licencia:

Creative Commons ReconocimientoNoComercialSinObraDerivada 4.0 Internacional

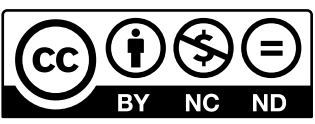

\section{Resumen}

El objetivo del artículo es analizar la restricción presupuestaria del municipio de Santander de Quilichao (Cauca) durante el periodo 2004-2016, mostrando el déficit fiscal primario de acuerdo a la teoría fiscal. La metodología abarca un análisis descriptivo de los gastos e ingresos, como componentes principales de la restricción presupuestaria, y además se presentan los índices de desempeño fiscal con el fin de analizar el comportamiento financiero de la entidad gubernamental, dada la presentación de indicadores fiscales del Departamento Nacional de Planeación -DNP-. Se concluye que la situación fiscal de Santander de Quilichao es sostenible y que la gestión de control en los gastos ha sido prudente en el periodo de referencia.

Palabras claves: Restricción Presupuestaria Fiscal, Gasto Público, Impuestos, Deuda, Desempeño Fiscal

\section{Abstract}

The aim of the article is to analyze the budget constraint of the municipality of Santander de Quilichao

Economista y Máster en Economía Aplicada, Docente, Colombia, eahernandezg@unal.edu.co, código ORCID: https://orcid.org/0000-0002-5919-7659

2 Economista, Profesional en Proyectos, Colombia, mayra.zapata@correounivalle.edu.co, código ORCID: https://orcid.org/0000-0001-6862-1426

3 Economista y Máster en Ciencias Económicas, Docente, Colombia, slgonzalezt@unbosque.edu.co, código ORCID: https://orcid.org/0000-0001-9771-017X

4 Ingeniero Comercial y Máster en Políticas Públicas y Sociales, Docente, Ecuador, AndresAnibal.Armas@alum.upf.edu, código ORCID: https://orcid. org/0000-0001-7760-4388 


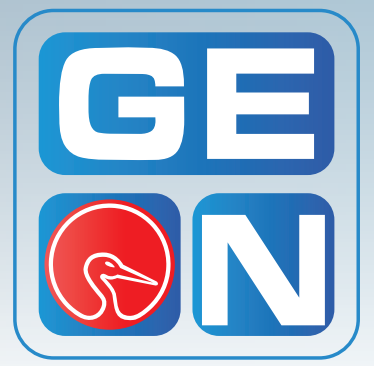

\section{Revista GEON}

(Gestión, Organizaciones y Negocios)

ISSN: 2346-3910 en línea

revistageon@unillanos.edu.co

Universidad de los Llanos

Colombia

Hernandez Garcia, E., Zapata Prado M., González-Tique, S., \& Armas-Moyano, A. (2020).

Restricción presupuestaria y desempeño fiscal de Santander de Quilichao - Colombia, 2004-2016.

\section{Revista GEON \\ (Gestión, Organizacionesy Negocios), 7(1). 179 - 204}

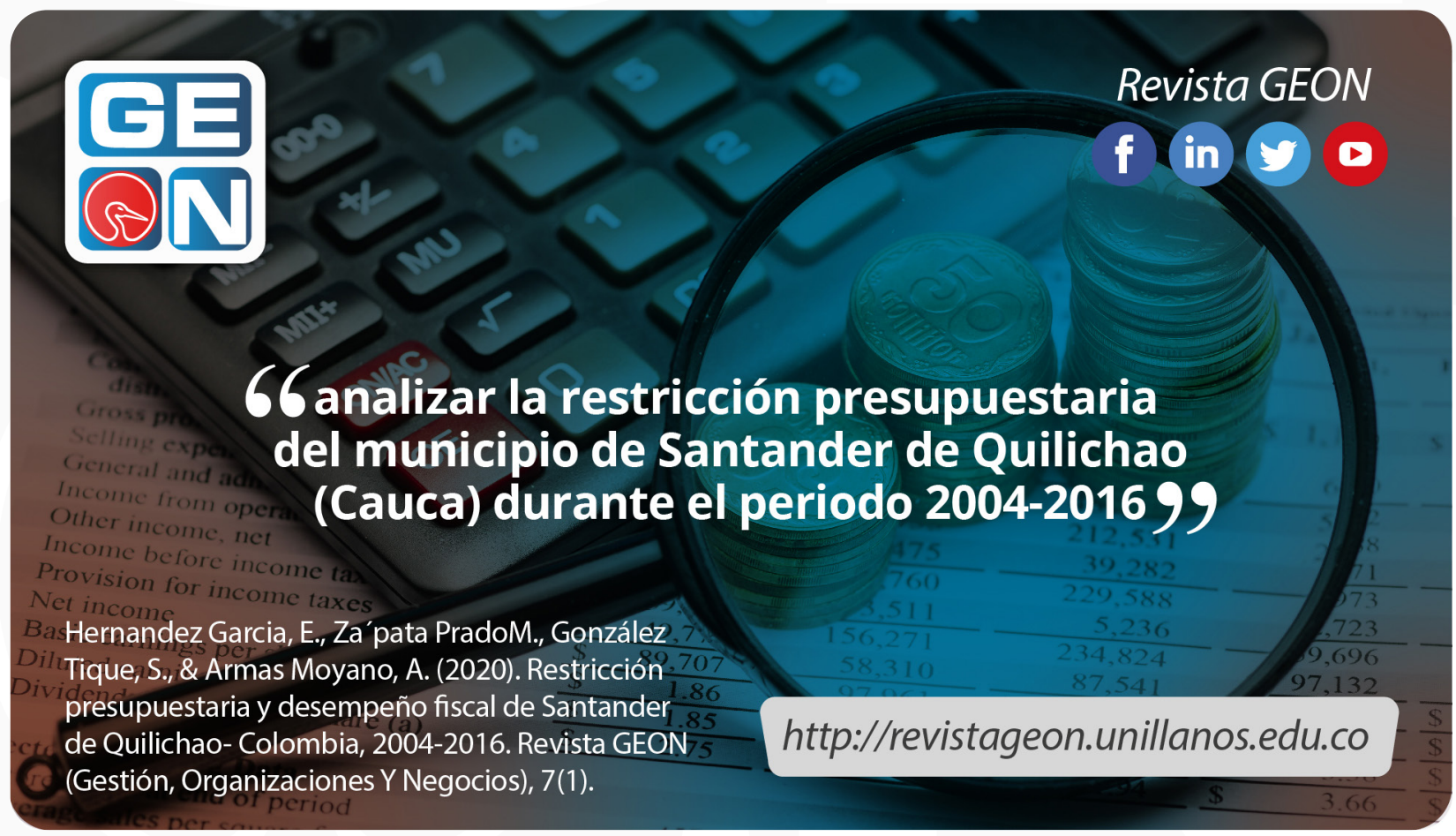


Cómo citar este artículo /

To reference this article:

Hernandez Garcia, E., Za' pata PradoM., González Tique, S., \& Armas Moyano, A. (2020). Restricción presupuestaria y desempeño fiscal de Santander de Quilichao- Colombia, 20042016. Revista GEON (Gestión, Organizaciones Y Negocios), 7(1) 179 - 204. https://doi. org/10.22579/23463910.201
(Cauca) during the period 2004-2016, showing the primary fiscal deficit according to the fiscal theory. The methodology includes a descriptive analysis of expenditures and income, as the main components of the budget constraint, and also presents the fiscal performance indexes in order to analyze the financial behavior of the government entity, given the presentation of fiscal indicators of the Department National Planning -DNP-. It is concluded that the fiscal situation of Santander de Quilichao is sustainable and that the management of control over expenses has been prudent in the reference period.

Keywords: Fiscal Budget Restriction, Public Expenditure, Taxes, Debt, Fiscal Performance

Codigos JEL: E62, H2O, H50, H61, H63

\section{Introducción}

Al hablar de política fiscal se hace referencia básicamente al manejo de las finanzas, ingresos y gastos del sector público; entendiendo este último junto con los impuestos como las variables de control que emplea el gobierno para conservar la estabilidad económica. Precisando que un sector público de alta calidad es aquel que cuenta con un sistema tributario eficiente y un sistema de egresos que reduce gastos improductivos e ineficientes; y que a su vez demanda un presupuesto suficientemente amplio para que el Estado cumpla su misión de forma óptima (Tanzi y Zee, 1997). Así mismo la política fiscal muestra formas de administrar públicamente los ingresos y gastos con el objetivo de invertir en proyectos que sirvan para mejorar la distribución de la riqueza, corregir las fallas del mercado, disminuir la desigualdad social y económica, entre otros (Delgado, Cárdenas y Fuentes, 2020).

Colombia tuvo un sistema fiscal centralizado en el que el Gobierno Nacional actuaba como principal recaudador de impuestos, asumiendo la mayoría de los gastos durante gran parte del siglo XX; ya a finales de los años sesenta se dieron los primeros pasos hacia el proceso de descentralización del país, el cual se vio fortalecido con el mecanismo de elección popular de alcaldes en los años ochenta y con la implementación de la Constitución Política de 1991 (DNP, 2010; Bonet y Pérez, 2019; Delgado et al. 2020).

Precisamente, en las disposiciones generales de la Constitución Política de 1991 está consignado que, como entidad esencial de la división político-administrativa del Estado, al municipio le corresponde prestar los 
servicios públicos determinados por la ley, construir las obras demandadas por el progreso local, ordenar el desarrollo del territorio de su jurisdicción, promover la participación de la comunidad, mejorar el nivel social y cultural de sus habitantes, y cumplir las demás funciones que le sean asignadas por la Constitución y las leyes.

Tal como afirman Alesina, Carrasquilla y Echavarría (2000) y, recientemente, Hernández y Barreto (2018), la descentralización en Colombia permitió a los entes territoriales tener mayores recursos y autonomía en el manejo de estos mismos; al aplicarse por parte del gobierno central un sistema de recursos y competencias basado en estadísticas socioeconómicas y de desempeño fiscal para asignar recursos a los gobiernos locales, los cuales, según afirma Oates (1999), pueden manejar de manera más eficiente los recursos al conocer de primera mano las necesidades y preferencias de la población.

Por lo tanto, los objetivos de este artículo son: (1) hacer un análisis de la restricción presupuestaria del municipio de Santander de Quilichao, (2) calcular el déficit fiscal primario como variable que permite medir mejor el impacto de la política fiscal en el municipio, y (3) analizar el desempeño fiscal según la metodología planteada por el Departamento Nacional de Planeación (DNP), que se compone del cálculo de los indicadores de: a) autofinanciación de los gastos de funcionamiento, b) respaldo del servicio de la deuda, c) dependencia de las transferencias y regalías de la Nación, d) generación de recursos propios, e) magnitud de la inversión; y d) capacidad de ahorro del municipio. Todo el análisis de política fiscal se llevará a cabo en el periodo 2004-2016. La información se recopiló directamente con el Departamento Administrativo de Hacienda Municipal ${ }^{5}$.

A continuación, el documento se divide en cuatro secciones incluida la introducción; en la segunda sección se presenta el marco teórico y de referencias relacionadas con la restricción presupuestaria a la luz de la teoría y política fiscal; en la tercera parte se presenta la metodología empleada para el análisis empírico, los procedimientos y resultados. Finalmente se encuentran las conclusiones.

\section{Contexto teórico}

Variedad de autores tratan el tema de la restricción presupuestaria y sus diferentes formas de aplicación. Desde la política fiscal, prestan atención especial a la relación entre deuda, déficit, gasto público e impuestos, planteando distintos escenarios en relación con política fiscal donde la restricción presupuestal desempeña un papel relevante.

Así es como Blanchard, Amighini, y Giavazzi (2017), valiéndose de las definiciones de organismos internacionales como el Fondo Monetario Internacional y el Banco Mundial, indican que el instrumento que contiene la proyección de la actividad financiera del Estado en determinado

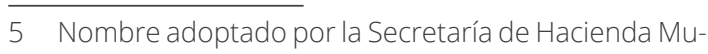
nicipal a partir de enero de 2017, una vez aprobado un proyecto de reestructuración administrativa. 
periodo de tiempo es el presupuesto público, constituyendo, una vez se aprueba por la ley, un compromiso con la comunidad. En la ejecución de tal presupuesto puede presentarse imprevistos que generan desequilibrios entre ingresos y egresos, que por lo general requieren ser financiados sin que para ello se disponga de recursos ya presupuestados, por lo que se hace necesario acudir a diferentes alternativas de financiamiento.

De manera que el déficit presupuestario corresponde al desequilibrio que hay entre los ingresos y gastos en cualquier nivel del Gobierno, y es un concepto enlazado a las actividades de financiación del sector gubernamental, el cual se usa con el fin de analizar los diversos escenarios de posibles ahorros financieros y también sobre mercados financieros y de capitales (Lora y Prada, 2016). El déficit presupuestario se expresa, en el periodo t, de la siguiente manera:

$$
\text { déficit }=i_{t} B_{t-1}+G_{t}-T_{t}
$$

$B_{t-1}$ corresponde a la deuda pública que existe al final del periodo anterior (t-1), i es la tasa de interés, $G_{t}$ es el gasto público, y $T_{t}$ son los ingresos obtenidos en el periodo t; por lo cual se traduce que el déficit presupuestario equivale al gasto, incluyendo los intereses pagados, descontando los ingresos.

Ahora, suponiendo que $G_{t}+i_{t} B_{t-1}>T_{t^{\prime}}$ se presenta un déficit positivo, lo cual indica que el sector público gasta en mayor cuantía de lo percibido en ingresos, haciendo necesario que se recurra a financiación a través de la emisión de bonos vía deuda pública $(\triangle B)$, o a la creación de dinero por medio del Banco Central para comprar bienes y servicios, y pagar la deuda emitida en el pasado $(\Delta M)$.

Considerando lo anterior, de manera general se formula la restricción presupuestaria del sector público así:

$G_{t}+i_{t} B_{t-1}=T_{t}+\Delta B+\Delta M$

Ahora, según Blanchard et al. (2017) el déficit de la ecuación [1] es el oficial pero no exacto en términos reales, por lo que la deuda del Estado debe expresarse en términos de bienes, esto es, el déficit en términos reales se debe expresar como:

déficit real $=i B_{t-1}+G-T-\pi B_{t-1}$

déficit real $=(i-\pi) B_{t-1}+G-T$

déficit real $=r B_{t-1}+G-T$

Los intereses reales de la deuda pública están representados por el término $r B_{t-1}$ y el déficit primario por $G-T$, que corresponde a la diferencia entre los gastos totales y los ingresos totales. Lora y Prada (2016), indican que el fin de esta medición es hacer una mejor aproximación de la presión ejercida por las actividades operacionales de las entidades públicas sobre los recursos económicas de un país o regiones, que otras medidas alternativas, refiriéndose especialmente al déficit convencional; y sostienen además que es útil también para observar qué tan sostenible es la política fiscal.

Los autores insisten en que no hay una manera determinada de definir el nivel sostenible del déficit públi$c 0$, e indican que, a pesar de lo anterior, en general es considerado que la política fiscal se torna insostenible cuando la situación económica vigen- 
te y proyectada del déficit fiscal permite un incremento persistente de la relación deuda sobre el PIB. En este orden, la sostenibilidad fiscal se refiere a las restricciones de largo plazo a las que debe hacer frente la política fiscal, íntimamente conectada con la dinámica de la relación deuda pública y PIB (Lora y Prada, 2016).

Ante el propósito de obtener un indicador operativo de sostenibilidad de la política fiscal, dichos autores consideran pertinente estudiar la dinámica de la deuda pública basada en el análisis de sus determinantes de crecimiento. De esta manera, suponiendo que el déficit fiscal convencional $\left(D C_{t}\right)$, tiene el incremento de la deuda interna como única fuente de financiamiento, se obtiene:

$D C_{t}=\underbrace{D D_{t}}_{\text {Deuda en el periodo t }}-\underbrace{D D_{t-1}}_{\text {Deuda en el periodo t-1 }}$ [4]

Ahora, retomando el concepto de déficit primario que es igual al convencional menos los pagos de interés, se reescribe la ecuación de la siguiente manera:

$$
D P_{t}=D C_{t}-\underbrace{i_{t-1}}_{\substack{t \\ \text { tasa dé interés } \\ \text { nominal }}} D D_{t}
$$

Combinando las ecuaciones [4] y [5], se tiene que

$D D_{-} t=D D_{t-1}+D C_{t}$

$D D_{t}=D D_{t-1}+D P_{t}+i_{t} D D_{t-1}$

Por lo tanto, en el periodo vigente (t) la deuda pública equivale a la deuda del período anterior (t-1) más el déficit primario del periodo corriente y los pagos de intereses por la deuda del periodo anterior.
Reordenando y dividiendo por la producción a precios corrientes:

$$
\begin{aligned}
& D D_{t}=\left(1+i_{t}\right) D D_{t-1}+D P_{t} \\
& \frac{D D_{t}}{Y_{t}}=\left(1+i_{t}\right) \frac{D D_{t-1}}{Y_{t}}+\frac{D P_{t}}{Y_{t}} \\
& d d_{t}=\left(1+i_{t}\right) \frac{D D_{t-1}}{Y_{t}}+d p_{t}
\end{aligned}
$$

Multiplicando y dividiendo el lado derecho de la ecuación [7] por $Y_{t-1}$

$d d_{t}=\left(1+i_{t}\right) \frac{D D_{t-1}}{Y_{t-1}} \frac{Y_{t-1}}{Y_{t}}+d p_{t}$

Ahora se multiplica y se divide el lado derecho de la ecuación [8] por $\left(1+\pi_{t}\right)$, donde $\pi_{t}$ corresponde a la inflación:

$$
\begin{aligned}
& d d_{t}=\left(1+i_{t}\right) \frac{D D_{t-1}}{Y_{t-1}} \frac{Y_{t-1}}{Y_{t}} \frac{1+\pi_{t}}{1+\pi_{t}}+d p_{t}
\end{aligned}
$$

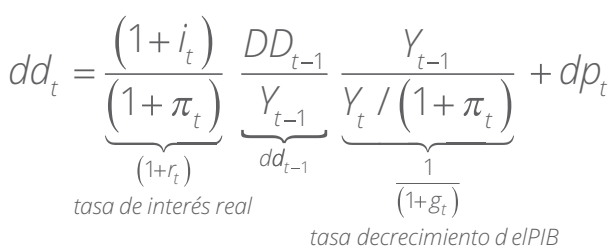

En este orden, se obtiene la ecuación que representa la relación entre el coeficiente de endeudamiento en el período corriente ( $\mathrm{t}$ ) y el período anterior (t-1); el cual incrementará o disminuirá a medida que haya déficit primario o superávit, respectivamente:

$$
\begin{aligned}
& d d_{t}=\left(1+r_{t}\right) d d_{t-1} \frac{1}{\left(1+g_{t}\right)}+d p_{t} \\
& d d_{t}=\frac{\left(1+r_{t}\right)}{\left(1+g_{t}\right)} d d_{t-1}+d p_{t}
\end{aligned}
$$

En cuanto al déficit primario sostenible $\left(d p_{t}^{s}\right)$, se supone que el coeficien- 
te de endeudamiento es constante en el nivel $\overline{d d}=d d_{t}=d d_{t-1}$, y reemplazando en la ecuación [10] se llega a:

$$
\begin{aligned}
& \overline{d d}=\frac{\left(1+r_{t}\right)}{\left(1+g_{t}\right)} \overline{d d}+d p_{t}^{s} \\
& d p_{t}^{s}=\overline{d d}-\frac{\left(1+r_{t}\right)}{\left(1+g_{t}\right)} \overline{d d} \\
& =\frac{\overline{d d}\left(1+g_{t}\right)-\left(1+r_{t}\right) \overline{d d}}{\left(1+g_{t}\right)} \\
& =\frac{\overline{d d}+\overline{d d} g_{t}-\overline{d d}-\overline{d d} r_{t}}{\left(1+g_{t}\right)} \\
& d p_{t}^{s}=\frac{\left(g_{t}-r_{t}\right)}{\left(1+g_{t}\right)} \overline{d d}
\end{aligned}
$$

Con esto, se puede deducir que deberá cumplirse tal relación para que la deuda como proporción del PIB permanezca constante; para que $d p_{t}^{s}>0$ sea sostenible, la tasa de crecimiento de la economía deberá ser mayor que la tasa de interés real de la deuda. Se tiene entonces que la diferencia entre el déficit primario observado y el déficit primario sostenible establece el ajuste fiscal necesario para asegurar la sostenibilidad, razón por la cual esta variable desempeña un papel fundamental en programas de estabilización macroeconómica (Lora y Prada 2016).

Las entidades gubernamentales tienen como responsabilidad general el orientar apropiadamente la asignación de los recursos públicos, procurando la optimización de los beneficios de la población y garantizando la sostenibilidad administrativa de la institución para su funcionamiento; esto es, generar acciones que les permitan tener un déficit fiscal primario sostenible. En la medida que las sociedades aumentan su complejidad, y sus grupos integrantes se vuelven más grandes y, por tanto, menos homogéneos, se hace necesario que el Estado asuma nuevas responsabilidades bajo el propósito de promover plenamente el bienestar de los individuos; y, a pesar que algunos problemas de la asignación de recursos se podrían resolver acudiendo a la reglamentación, generalmente el Estado demanda recursos para cumplir esta labor (Tanzi, 2000).

Conforme a las funciones que tiene el Estado, se han dado diferentes connotaciones al término de las finanzas públicas, lo cual corresponde esencialmente a factores históricos, el nivel de desarrollo de cada economía y la forma de gobierno (Conchas, 2001). Dado esto, es normal encontrar abundante literatura en la que se tratan cuestiones referentes a este tema; ya sea mediante el estudio individual de los componentes de la restricción presupuestaria, su impacto en la economía regional o nacional, o en determinados sectores de la misma como lo son la salud o la educación; a continuación se referencian algunos enfoques.

Por ejemplo, Giraldo (2009) presenta un cuadro general de las finanzas públicas para países en desarrollo haciendo énfasis en América Latina, mediante la presentación sistemática de las variables gasto, presupuesto, descentralización e ingresos públicos; afirmando que las finanzas públicas reflejan, entre otras cuestiones, 
la prioridad que la sociedad da al gasto social respecto a otros gastos; partiendo de que la asignación de recursos públicos se deriva de un acto político, porque aunque tiene efectos sociales, económicos, y políticos, el criterio con que se asignan tales recursos está basado en postulados ideológicos justificados como producto de la búsqueda de equidad, eficiencia, y el bien común, a fin de respaldar las decisiones adoptadas.

Por su parte Fergusson y Suárez (2010) y Amieva (2014) afirman que una postura radical y carente de sustento empírico es la de las variaciones en la posición fiscal que afectan al PIB, esto es, la hipótesis de equivalencia ricardiana, la cual indica que los déficit fiscales encaminan hacia un cambio en el ahorro privado, y esta idea, asociada con la de Robert Barro, soporta que las decisiones de consumo están basadas en una estrategia de optimización respecto a un amplio horizonte de tiempo, de manera que los agentes económicos moldean su ahorro y consumo en consideración a los ingresos netos después de impuestos que esperan en el futuro. Así, como déficits más elevados pueden constituir impuestos futuros, los consumidores responden al incremento en los déficits gubernamentales con un aumento en su ahorro personal, contrarrestando cualquier efecto de los déficits públicos sobre el PIB.

Para Colombia se referencian trabajos como el de Sánchez, Gutiérrez y Parra (1994), que realizan un análisis descriptivo y econométrico de las finanzas a nivel regional, departamental y municipal para el periodo de
1980 a 1991; bajo el objetivo de determinar el impacto de los ingresos tributarios, no tributarios y transferencias, es decir, de la estructura de la financiación, en la estructura del gasto (funcionamiento e inversión). Esto, mediante la estimación de los coeficientes de la estructura del gasto de funcionamiento, inversión e ingresos tributarios en un modelo de ecuaciones simultáneas, donde el endeudamiento se incorpora de forma implícita como la diferencia entre gastos e ingresos.

Los autores muestran que los departamentos que tienen un mayor nivel de pobreza destinan al pago de sus gastos corrientes el total de los ingresos tributarios, el 78\% de los ingresos no tributarios y el 93\% de las transferencias; mientras que, con el mismo fin, los departamentos con mejor nivel económico destinan casi la mitad de sus ingresos tributarios, el 69\% de sus ingresos no tributarios y la totalidad de sus transferencias. Los resultados del análisis demuestran de igual manera que no hay una relación clara entre las transferencias y el esfuerzo fiscal del ente territorial, por lo que no es posible comprobar la hipótesis de pereza fiscal en ninguna de las entidades territoriales. En la misma dirección Cadena (2002) rechaza la hipótesis de que el incremento de las transferencias genera poco estímulo del esfuerzo tributario, es decir, rechaza la pereza fiscal en los entes territoriales.

Lo anterior podría verse también en la eficiencia de los gobiernos locales en el suministro de los bienes y servicios públicos, ya que la competencia 
reside en la ventaja de la provisión local por parte de las administraciones municipales partiendo del hecho de que pueden hacer una mejor identificación de las preferencias y necesidades de los integrantes en sus municipios, lo cual se conoce como la hipótesis de Tiebout (1956). De esta manera, las decisiones que toman los individuos respecto al consumo y/o suministro de bienes públicos y su financiación con recursos transferidos o propios, conlleva a una asignación Pareto eficiente, la cual es similar a las decisiones que toman los demás agentes económicos como empresas y personas sobre los bienes privados (Lozano, 1999).

Bonet, Pérez y Montero (2018) para el periodo 1996-2015 demuestran que la descentralización en estas dos décadas logró robustecer las finanzas municipales y departamentales, con especial énfasis en los municipios, al tiempo que el mejor direccionamiento del gasto en inversión ha llegado a todos los niveles sociales, generando mayor dinamismo en la inversión socialy, por lo tanto, desarrollo económico local con importantes reducciones de la pobreza y mejora en la calidad de vida de la población en general.

Por su parte, Ospina y Gutiérrez (1996) estudian el comportamiento de las finanzas municipales para el periodo comprendido de 1993 a 1995, haciendo uso de una muestra de 629 municipios, clasificados en grupos de acuerdo al tamaño poblacional; y presentan la variación en la estructura de ingresos, gastos y balance financiero de 1980 a 1994, con el propósito de mostrar el impacto de la Ley 60 de 1993 en las finanzas de los municipios. Los resultados de los autores resaltan el aumento de las transferencias a partir del año de 1993, el cual fue muy elevado en consideración al registrado por las otras fuentes de ingresos. De igual manera, destacan que no hubo pereza fiscal, pues entre 1993 y 1994 los ingresos tributarios mostraron un crecimiento real de $10 \%$, respecto a un crecimiento real promedio por año de $7 \%$ entre 1990 y 1993; y también concluyen que municipios con mayor población son los que reportan una mayor capacidad fiscal total.

Ocampo (1997), evalúa la situación fiscal de Colombia, exponiendo que las diferentes metodologías de medición del gasto permiten revelar la evolución y fuentes de crecimiento del mismo; concluyendo, mediante un análisis de las mediciones del Departamento Nacional de Planeación y del Banco de la República, que el Estado como demandante ha crecido más, aunque en niveles menores a los señalados comúnmente, y como productor de bienes y servicios el ha crecido relativamente poco. Destaca además que el ítem más dinámico del gasto público son las transferencias de la seguridad social, en las cuales el sector público opera significativamente.

Por su parte Ocampo (1997) exhibe la dinámica de la deuda pública a nivel nacional y del déficit del sector público consolidado, sosteniendo que en la literatura existente sobre el tema se admite que no hay una única medida del déficit que permita resumir la información necesaria y, por ende, la forma en que se mide el déficit depende del objetivo de cada análisis; aun- 
que la metodología de operaciones efectivas de caja es la más popular, dado que mide las necesidades del Gobierno en cuanto al financiamiento y la presencia que éste tiene en los mercados internos y externos de capitales. De esta manera, Ocampo (1997) muestra que el déficit primario revela cómo los compromisos actuales del Gobierno afectan las necesidades de financiamiento y refleja de manera más precisa sus operaciones reales.

Con su análisis, Ocampo (1997) también muestra la evolución del déficit real y primario del Gobierno Nacional, permitiendo apreciar que la brecha entre éstos se amplía a partir de 1995, a medida que el pago de intereses abarca una mayor parte de los pagos totales del Gobierno; y que a pesar que se espera que el déficit real se continúe expandiendo para el año de 1997, el déficit primario presenta una reducción, ajustado por la variación de las cuentas por pagar. De esta manera, afirma el autor que tal medición muestra de manera precisa el esfuerzo de ajuste del gasto corriente y hace aún más evidente la forma en que la dinámica del pago de intereses de la deuda pública ha venido determinando la evolución del déficit fiscal.

Por otra parte, Zapata (2010) indica en su estudio que el modelo de financiamiento de los gobiernos territoriales en el país es más cercano a lo que en teoría económica se determina como federalismo fiscal; y así mismo, manifiesta que hay un considerable volumen de recursos involucrados, tanto propios de los departamentos y municipios como del sistema de transferencias, el cual ordena gran parte de los recursos nacionales a los territorios, permitiendo que los go- biernos territoriales gocen de mayor autonomía política y fiscal, amparándola de permanentemente frente al gobierno nacional.

Mediante el análisis de los recursos propios y transferidos de departamentos y municipios de Colombia, el autor da evidencia de que para el periodo comprendido de 2002 a 2008 la autonomía de los territorios no provocó pereza fiscal, mostrando por el contrario, que en el último cuatrienio de estudio los ingresos corrientes fueron aún más dinámicos que las transferencias. Además, identifica patrones generales de las principales fuentes de recursos de los gobiernos territoriales, afirmando que el monto de tales recursos es y ha sido muy alto, y continuará aumentando en el largo plazo, por lo que la más viable y única elección para las finanzas territoriales es propender su fortalecimiento y mejor asignación (Zapata, 2010).

A nivel regional, López, López y Mesa (2014) muestran que la administración y los respectivos recursos públicos juegan un papel importante en el desarrollo local, poniendo a prueba la correlación positiva que se presenta entre estas variables para los municipios del departamento de Antioquia, de tal manera que finalmente y a través de metodologías descriptivas, prueban la respectiva hipótesis del buen manejo de la hacienda pública municipal y la calidad de vida de sus habitantes. Resultados que concluyen también Bonet et al. (2018) al afirmar que el mayor crecimiento económico de los gastos de inversión en los municipios, por encima del gasto de funcionamiento, trajo consigo mejoras en la calidad de vida de los municipios y reducción de la pobreza y miseria. 
Por su parte Gamarra (2013) señala que en Colombia la sostenibilidad de las finanzas está estrechamente ligada a la capacidad de gestión que tienen las entidades públicas con respecto al gasto e ingreso, proporcionando un direccionamiento adecuado de las finanzas públicas y reducción en la dependencia del financiamiento externo, así como el establecimiento de métodos para la generación de recursos propios que garanticen suficiencia económica y financiera.

Se puede apreciar, por lo tanto, que hay variedad de autores que con sus estudios contribuyen en la investigación del déficit público, demostrando la importancia de resolver tal situación en las entidades gubernamentales bajo el propósito de alcanzar presupuestos sostenibles. Si no se realiza el debido ajuste en las finanzas públicas, es probable que se generen choques tanto en el orden interno como en el orden externo, conllevando a que se realicen ajustes bruscos del gasto público, y por tanto, a panoramas de recesión, desempleo, devaluación u otros posibles factores que podrían alterar directamente a los estratos socioeconómicos más vulnerables de la sociedad.

\section{Materiales y métodos}

Para la consolidación de las series empleadas se solicitó al Departamento Administrativo de Hacienda Municipal (DAHM) del municipio de Santander de Quilichao, información histórica de las ejecuciones presupuestales (ingresos y gastos) del municipio entre los años 2004 y 2016. El formato en el que estas se encuentran consignadas corresponde al método de Operaciones Efectivas de Caja, la cual es acorde con la normatividad que rige el Sistema Presupuestal Público de Colombia, en la que se incluyen los gastos de funcionamiento desagregados en sus principales ítems.

Los datos se transforman a precios constantes con el Índice de Precios al Consumidor nacional de 2008. Para calcular el déficit del municipio, se acude al marco teórico expuesto, y se procede a realizar su análisis descriptivo al igual que el del resto de componentes de la restricción presupuestaria: ingresos, gastos y deuda pública.

Finalmente, se procede a realizar el cálculo de los índices de desempeño fiscal de la institución gubernamental. Para esto, se recurrirá a la metodología empleada por el DNP, que a través de los índices expuestos en la siguiente Tabla 1 mide el desempeño fiscal de las entidades municipales y departamentales.

Tabla 1. Indicadores Fiscales según el DNP

Autofinanciación del funcionamiento =

Gasto funcionamiento

Ingresos corrientes de libre destinación

Magnitud de la deuda $=$

Servicio de la deuda

Ingresos disponibles

Dependencia de las transferencias =

Transferencias + Regalías + Otras transferencias Ingresos total

Generación de recursos propios =

Ingresos tributarios

Ingresos corrientes

Magnitud de la inversión =

Gastos en inversión

Gasto total

Capacidad de ahorro $=$

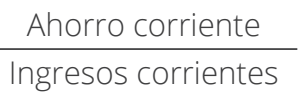

Fuente: Departamento Nacional de Planeación (DNP). 


\section{Resultados y discusiones}

Bajo el propósito de estudiar la restricción presupuestaria del municipio de Santander de Quilichao y el comportamiento de cada uno de sus componentes para el periodo de 2004 a 2016, se realiza a continuación un análisis descriptivo de los datos. En primer lugar se analizan los ingresos corrientes (tributarios y no tributarios), luego se visualizan los gastos y la deuda, después se presenta el déficit fiscal primario y finalmente se examinan los indicadores de desempeño fiscal presentados en la Tabla 1.

\section{Análisis de los ingresos del municipio}

Los ingresos del municipio se componen en primera instancia por los recursos percibidos por tributación y los no tributarios -que corresponden al cobro por la prestación de los servicios públicos, derechos tributarios, producción, distribución, explotación de bienes y servicios-. Se encuentran también dentro de estos recursos los fondos especiales, fondo local de salud, rentas ocasionales y los recursos de capital.

Para el periodo 2004 a 2016, en promedio los ingresos tributarios corresponden a un $47 \%$ del total de los ingresos corrientes, mientras los no tributarios representan el 53\% restante. Se observa en el Gráfico 1 que para el año 2016, la situación es inversa, pues los recaudos tributarios tienen una participación mayor, del 52\%, mientras los no tributarios representan el $48 \%$ del total de los ingresos no corrientes. En general, se aprecia que la distribución de los ingresos corrientes es aproximadamente similar entre los ingresos por impuestos y los que no provienen mediante dicha vía fiscal.

Así mismo, el Gráfico 1 permite observar que la tendencia de los ingresos corrientes y sus componentes (tributarios y no tributarios) ha sido en general con tendencia creciente. Los ingresos tributarios muestran un comportamiento menos fluctuante en el periodo, consistente con resultados como lo de Sánchez et al. (1994) que indican que la estructura tributaria concentra los ingresos de menor volatilidad que los no tributarios, lo cual también es bastante positivo en términos del indicador No. 4 de generación de recursos propios que se explica más adelante.

Gráfico 1. Ingresos Corrientes

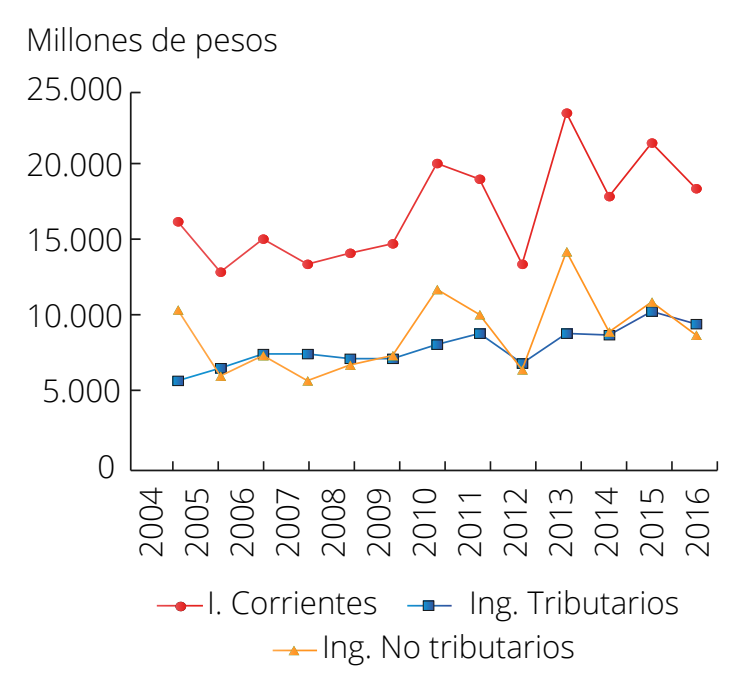

Fuente: cálculos propios a partir de los datos del DAHM.

Por su parte, en el Gráfico 2 se observan los ingresos tributarios, que se componen de impuestos tributarios directos e indirectos, $16 \%$ y $84 \%$ 
respectivamente para el año 2016. Se puede apreciar en este Gráfico que la mayor parte de los impuestos son indirectos, lo cual es consiste con la estructura de impuestos colombiana al día de hoy, que desde mediados de los años sesenta del siglo XX cuando se introdujo el impuesto a las ventas y el impuesto al valor agregado aprobado a mediados de los ochenta, además de las continuas reformas tributarias, han hecho que la tributación indirecta tome un papel de importancia mayor y creciente que la tributación directa (Junguito y Rincón, 2004).

Gráfico 2. Ingresos Tributarios

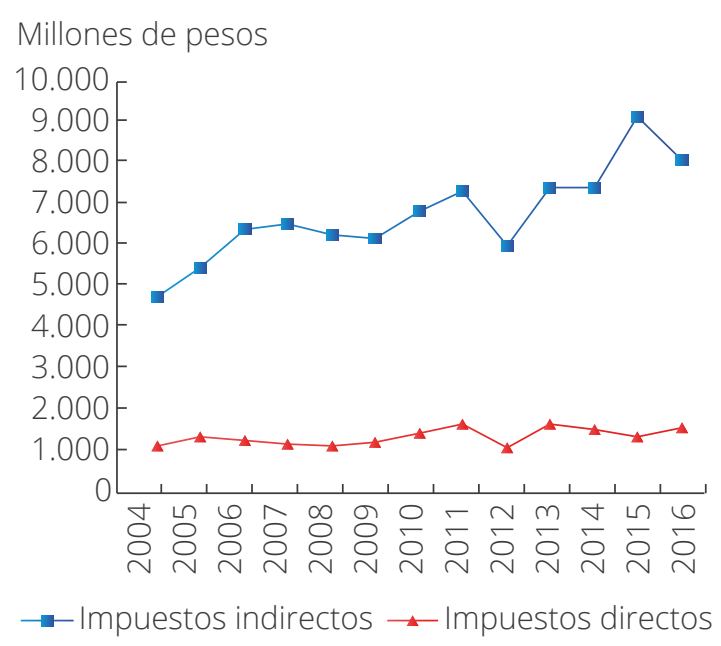

Fuente: cálculos propios a partir de los datos del DAHM.

Para el municipio de Santander de Quilichao, los impuestos directos se componen por los recaudos de predial unificado, sobretasa ambiental, circulación y tránsito de vehículos públicos. El Gráfico 3 Panel A muestra la evolución de estos impuestos tributarios. Por ejemplo, el predial unificado que es el impuesto que recae sobre cada predio ubicado dentro de la ju- risdicción del municipio, el cual abarca la tasa predial, los impuestos por arborización y de parques, por estratificación socioeconómica y de sobretasa al levantamiento catastral; dicho impuesto representa la mayor parte de los impuestos tributarios directos del municipio, aproximadamente en todo el periodo del $74 \%$ en promedio.

En cuanto al impuesto de la sobretasa ambiental, es el recaudo hecho destinado a la Corporación Autónoma Regional del Cauca para protección del medio ambiente y de recursos naturales renovables, conforme lo establece la Ley 99 de 1993 en su artículo 44. De acuerdo a los datos disponibles, se sumó como rubro de los recaudos de Santander de Quilichao a partir del año 2010 y, en promedio, representa el $7 \%$ en el periodo.

El tercer impuesto directo aquí considerado es el de circulación y tránsito de vehículos públicos, que son las tarifas cobradas por concepto de circulación y tránsito de vehículos de carga y de transporte público de pasajeros. Este impuesto se ha mantenido más o menos en la misma proporción, con un promedio del 19\% en el periodo analizado, con un máximo del 28\% para el año 2014 y cayendo al 16\% y 15\% para los años 2015 y 2016 respectivamente (Gráfico 3).

Por otro lado, el Gráfico 4 permite ver los impuestos indirectos del municipio y que representan la mayor fuente de ingresos tributarios, los se componen principalmente y cerca del 90\% para el promedio del periodo por cuatro rubros, a saber: industria y comercio (52\%), sobretasa a la gasolina (28\%), estampillas pro-cultura y adulto mayor (6\%), avisos y tableros (4\%). 
Los recaudos por industria y comercio que tienen la mayor participación en el total de impuestos indirectos, corresponden a los impuestos de los cuales son sujeto pasivo los bancos, corporaciones de ahorro, de vivienda o financieras, las compañías de financiamiento y demás establecimientos de crédito definidos por la Superintendencia Financiera y que operan en Santander de Quilichao. Seguido, por magnitud de representación, se tienen los ingresos por concepto de sobretasa a la gasolina y son las obligaciones que surgen en el momento de enajenación del combustible. Por su parte, el impuesto de estampillas ha ganado una participación importante, pasando del 1\% en el año 2004 al 10\% para el año 2016; en términos de la política fiscal relacionada con el desarrollo social y cultural, es interesante que dicho rubro de tributación haya mejorado en participación, ya que así mismo la inversión en lo social y cultural crece.

Gráfico 3. Impuestos Directos

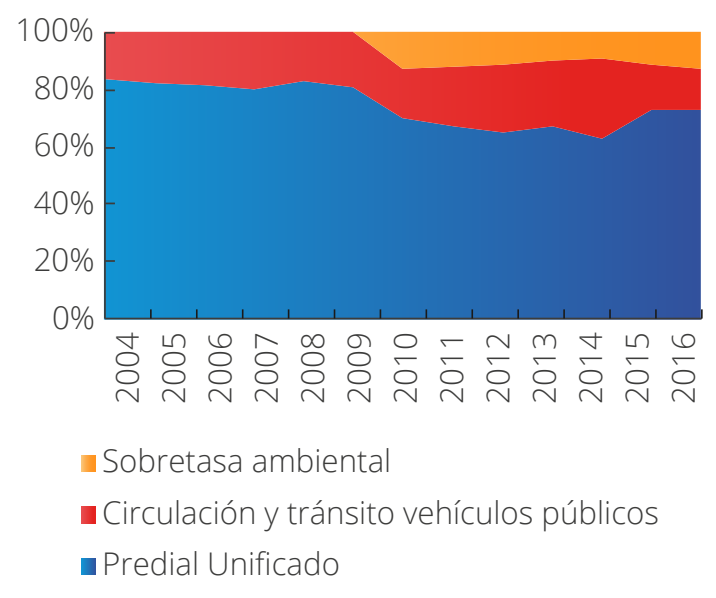

Fuente: cálculos propios a partir de los datos del DAHM.
Gráfico 4. Impuestos Indirectos

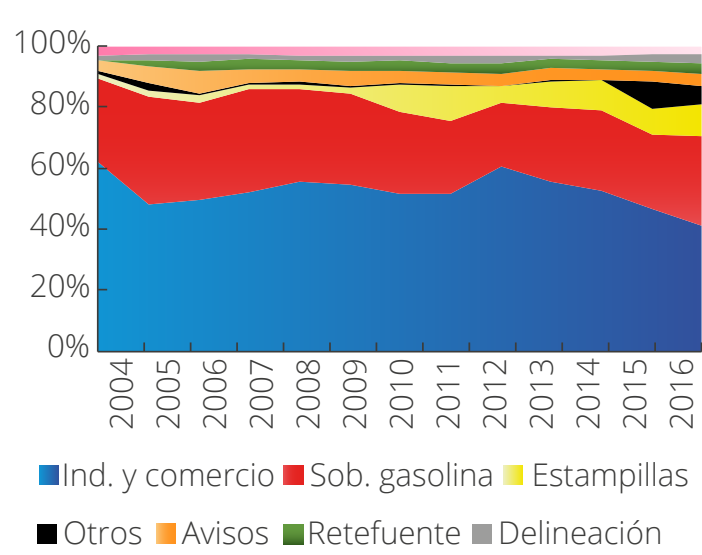

sob. Bomberil

Fuente: cálculos propios a partir de los datos del DAHM.

Por otra parte, en el Gráfico 5 los ingresos no tributarios y que representan alrededor del 53\% de los ingresos del municipio, se componen de: a) las transferencias que son recursos percibidos de otros niveles del Estado (88\% de los ingresos no tributarios); b) tasas y derechos, que son los ingresos por prestación de servicios técnicos, administrativos, médicos, culturales y públicos (5\%); c) los fondos especiales que son los ingresos creados y definidos por acuerdos o leyes para la prestación de servicios públicos específicos como vivienda, salud, seguridad o vehículos (4\%); d) las multas y sanciones que son los montos cobrados por el municipio, fundamentados en títulos jurídicos (3\%).

En el Gráfico 6 se observa la evolución de cada rubro de los ingresos no tributarios mencionados en el párrafo anterior. De ellos, se puede observar que las transferencias por parte del Estado colombiano desempeñan un 
papel fundamental en la evolución de estos ingresos, y especialmente las transferencias realizadas mediante el Sistema General de Participaciones, las cuales participan aproximadamente con el $41 \%$ del total de ingresos corrientes del municipio.

Gráfico 5. Ingresos no Tributarios por total ítem

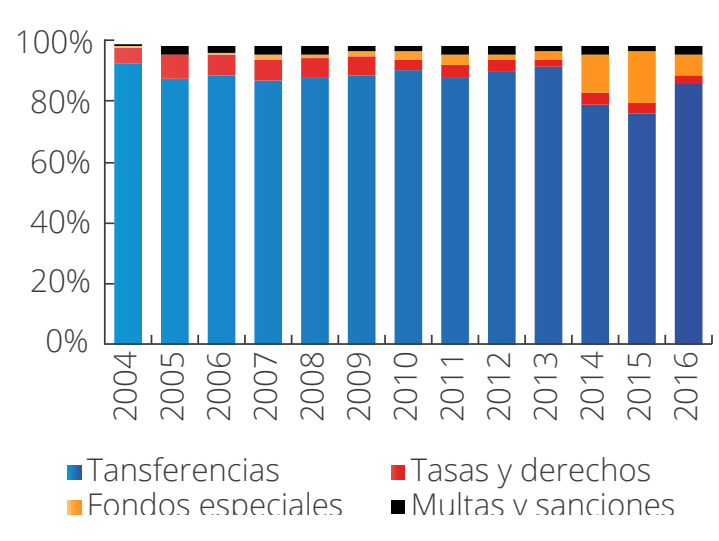

Fuente: cálculos propios a partir de los datos del DAHM.

El Gráfico 6 permite analizar lo que sucede en el tiempo con cada uno de los ingresos no tributarios mencionados antes y desglosados según sus componentes. Así, se evidencia el comportamiento desglosado de las transferencias al municipio. A lo largo del periodo, las transferencias son representadas en promedio en un 79\% por los recursos del Sistema General de Participaciones, que son aquellos recursos cedidos por el gobierno nacional para libre destinación por parte del gobierno municipal con el propósito de que realice operaciones financieras y de inversión que incentiven determinados sectores económicos que impulsen el desarrollo económico local (Bonet y Pérez, 2019).

La cofinanciación, por su parte, es instrumento para la ejecución local con el fin de orientar la inversión pública de los municipios a sectores prioritarios en los cuales el Gobierno Nacional tiene algún interés particular y representa el $17 \%$ del total de las transferencias del periodo. Los picos que se observan en el Gráfico 6 se deben a que en 2010 el municipio recibió ingresos para proyectos como el Matadero Municipal, mejoramiento de vía rural, hogares infantiles y SISBÉN; y en 2013 para la construcción de la vía entre San Antonio y San José.

En cuanto a las tasas y derechos, el Gráfico 7 muestra que el mayor recaudo percibido fue del $43 \%$ y proviene del alquiler de locales en la plaza de mercado del municipio; seguido del ingreso percibido por la ocupación de vías con materiales o desechos sin la debida licencia, por ocupación por más tiempo del autorizado o por roturas o excavación de las vías, que apor$\tan 25 \%$ en promedio para el periodo.

De su lado, los fondos especiales del municipio constituyen el $4 \%$ de los ingresos no tributarios (Gráfico 8) y presentan un comportamiento creciente, exceptuando 2012 y 2016 donde decrecen considerablemente. Entre 2013 y 2015 se aprecia un crecimiento significativo, que se debe a los ingresos percibidos por el fondo de seguridad y fondo de vigilancia.

Para finalizar la presentación de los ingresos no tributarios del municipio, el Gráfico 9 permite analizar la variable de multas y sanciones con cierta variabilidad en los datos. De estas multas y sanciones impuestas en Santander de Quilichao entre 2004 y 2016, las más representativas son las de trán- 
sito y transporte, que aportan el 98\% de los ingresos totales promedio.

Gráfico 6. Ingresos no tributarios: Transferencias

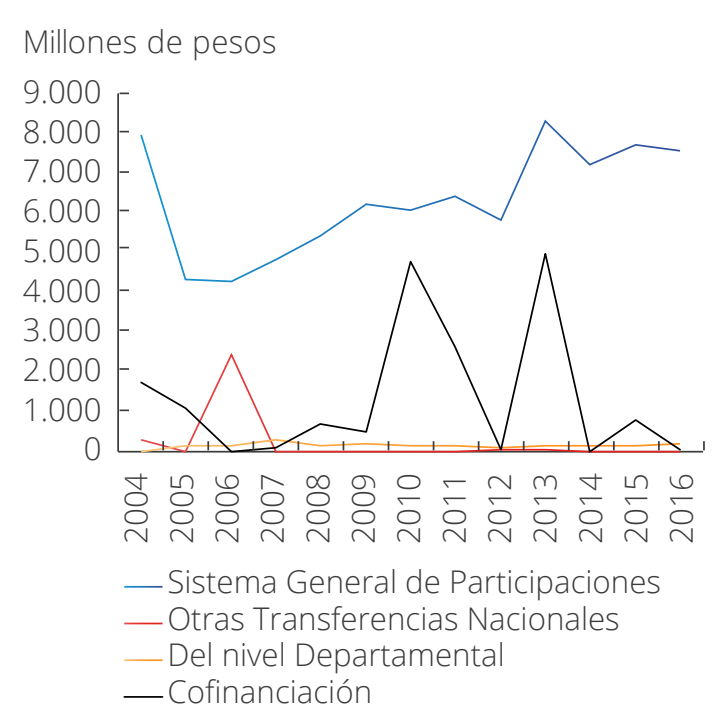

Fuente: cálculos propios a partir de los datos del DAHM.

Gráfico 7. Ingresos no tributarios: Tasas y Derechos

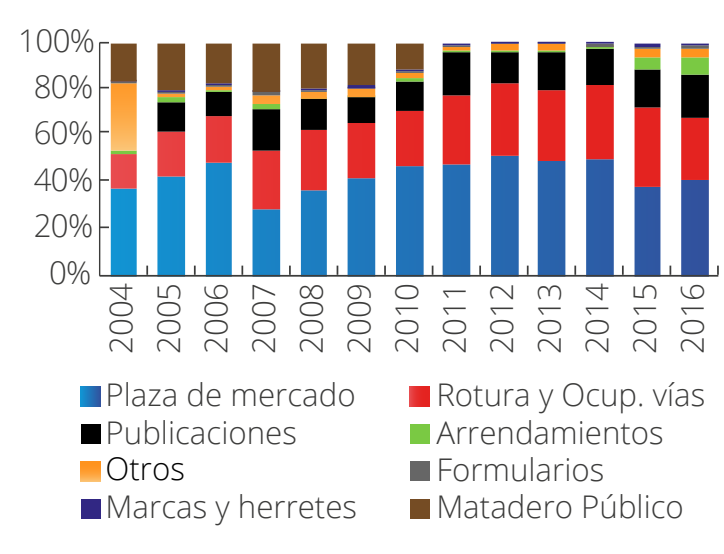

Fuente: cálculos propios a partir de los datos del DAHM.
Gráfico 8. Ingresos no tributarios: Fondos Especiales

Millones de pesos

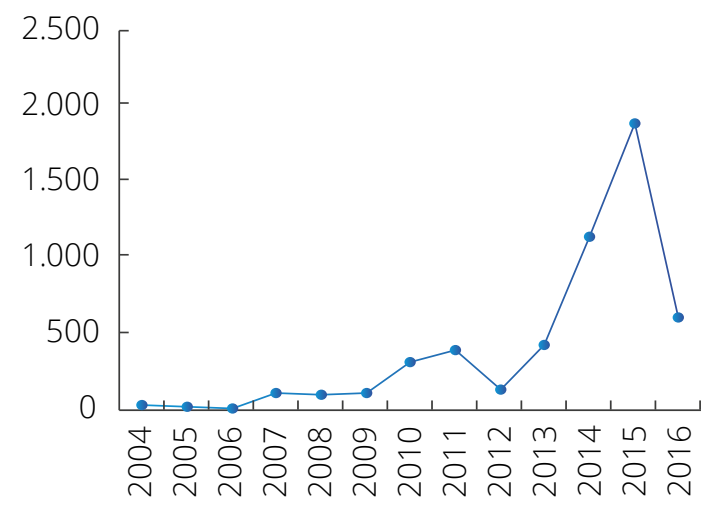

Fuente: cálculos propios a partir de los datos del DAHM.

Gráfico 9. Ingresos no tributarios: Multas y Sanciones

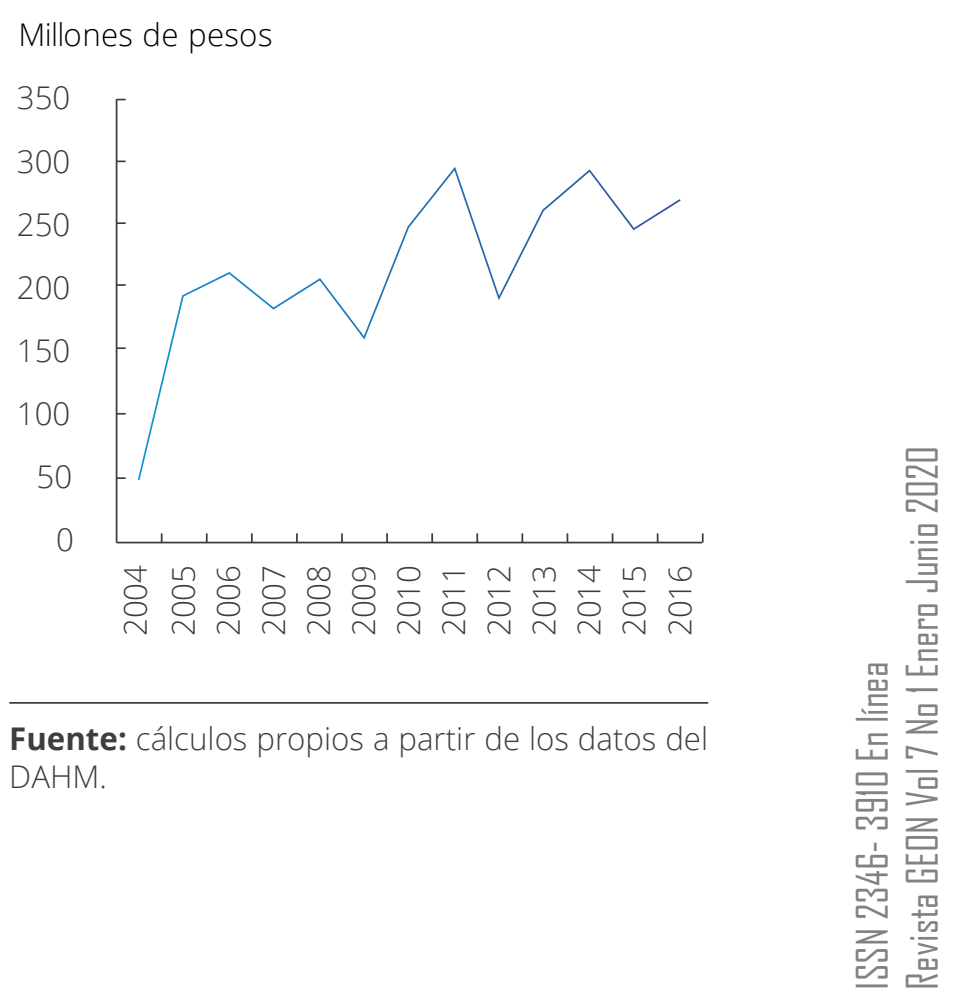




\section{Análisis de los gastos del Municipio}

Los gastos del municipio se componen principalmente de cinco rubros: (1) gastos de funcionamiento de la Administración Central, (2) gastos de funcionamiento del Concejo, (3) gastos de funcionamiento de la Personería Municipal, (4) gastos de inversión, (5) servicio de la deuda pública. Estos ítems de gastos se destinan a la formación de infraestructuras y a la adquisición de productos necesarios que sirvan al funcionamiento de las diferentes actividades y servicios prestados por las entidades gubernamentales del municipio, así como también aquellos otros gastos que con carácter de amortizables.

De esta manera el Gráfico 10 permite observar la evolución de cada uno de estos rubros. El gasto de inversión es quien tiene la mayor participación y además creciente desde el año 2004 hasta al año 2016, lo que en términos del desarrollo económico para el municipio es importante, porque como se puede ver en el Gráfico 11, la mayor parte de este gasto es en variables del capital humano, que a la luz de las diversas investigaciones, teóricas y empíricas, sus efectos son positivos sobre la reducción de la pobreza, el incremento de ingresos, mejora en los retornos de los individuos y organizaciones, entre otras variables del desarrollo (Ray, 2002; Weil, 2006).

Adentrándose en cada rubro del gasto, el Gráfico 11 permite ver que los gastos de inversión están constituidos principalmente por el financiamiento del servicio de salud en el municipio, aproximadamente con el 60\% en promedio para todo el periodo. Dentro de dichos gastos se encuentran los del Régimen Subsidiado de Seguridad Social en Salud -que representan al rededor del 95\% del total de este gasto-; el otro 5\% se distribuye en gastos del Sistema de Atención a la Comunidad, apoyo a poblaciones especiales e instituciones, reserva e infraestructura de salud.

Gráfico 10. Gastos del municipio

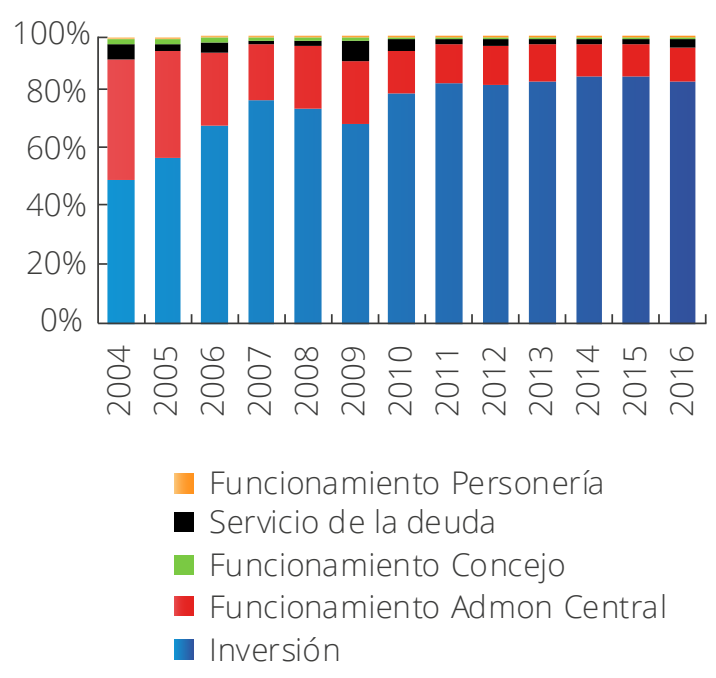

Fuente: cálculos propios a partir de los datos del DAHM.

El segundo rubro de inversión es la educación, que como es bien sabido se considera un instrumento para apuntar a la igualdad social y crecimiento económico, dado que a mayor nivel educativo mayores son las posibilidades de acceder a empleos más productivos y con mejor remuneración (Becker, 1993; Barro y Lee, 2010). En el periodo estudiado representa aproximadamente el 12\% del gasto en inversión del municipio. 
El comportamiento del resto de las variables del gasto en inversión, han sido relativamente estables, especialmente la inversión en programas o proyectos de atención a grupos vulnerables, agua potable y saneamiento, promoción del desarrollo, cultura, fortalecimiento institucional $y$, prevención y atención de desastres. Es preciso tener en cuenta que las variaciones que se presentan en estos gastos de inversión se deben principalmente a la priorización que se da en cada administración a cada rubro, conforme a su plan de gobierno.

Gráfico 11. Porcentajes Gastos de Inversión (20042016)

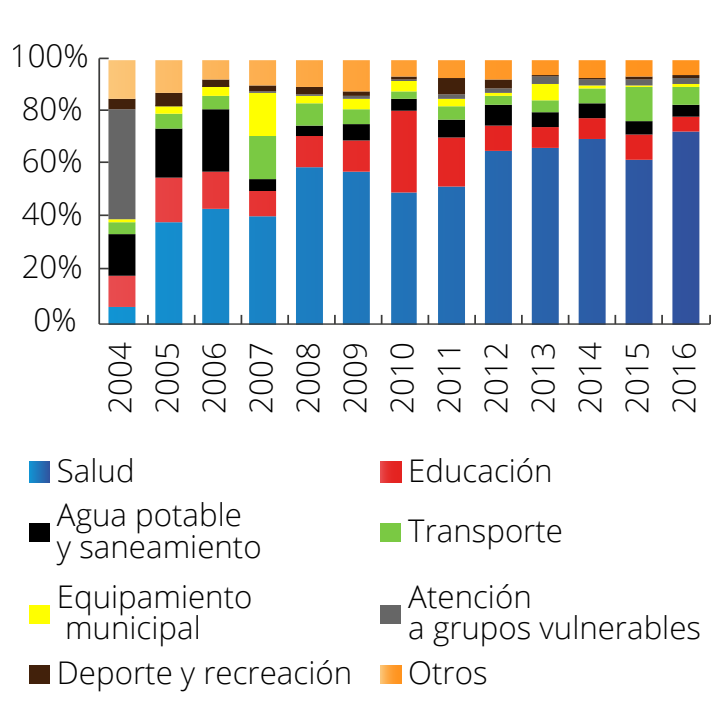

Fuente: cálculos propios a partir de los datos del DAHM.

Por su parte, en el Gráfico 12 se aprecia una tendencia creciente en los gastos de personal como parte de los gastos de funcionamiento de la Administración Central, mientras que en los otros dos rubros se mantienen constantes en el periodo de análisis. Los gastos asociados a las retribuciones al personal corresponden al 59\% del total de estos gastos, mientras que los gastos generales o referentes a la adquisición de los bienes y servicios necesarios para que la Administración Central cumpla con las funciones asignadas por ley, representan el 21\% del total de este rubro; las transferencias -apropiaciones destinadas a la previsión y seguridad social-, equivalen al 20\% de los gastos de funcionamiento de la administración.

Así mismo, en el Gráfico 13 se observan los gastos de funcionamiento del Concejo, que representan el $0,8 \%$ de los gastos totales del municipio en el periodo. Del total de estos gastos de funcionamiento, el 87\% corresponde a gastos de personal y el $13 \%$ a gastos generales del Concejo. Por su parte, los gastos de la Personería constituyen el $0,3 \%$ del gasto total del municipio. De este gasto de Personería, el 89,3\% equivale a los gastos de personal y el $10,7 \%$ a los gastos generales de la Personería.

Gráfico 12. Gastos de Funcionamiento: Administración Central

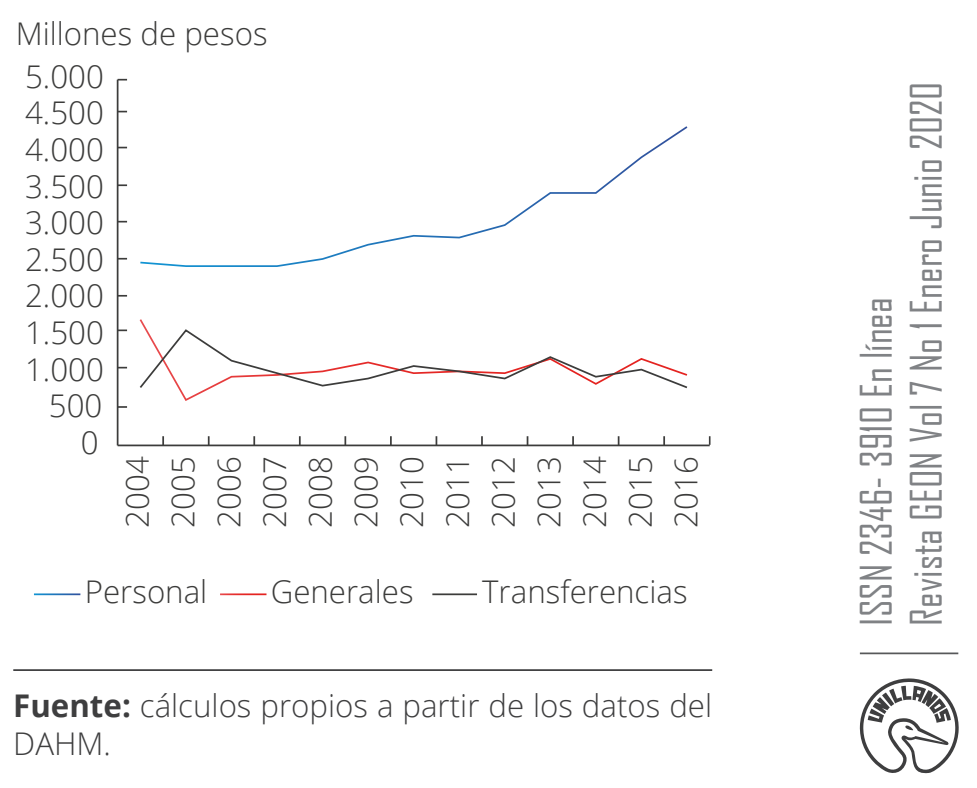


Gráfico 13. Concejo y la Personería

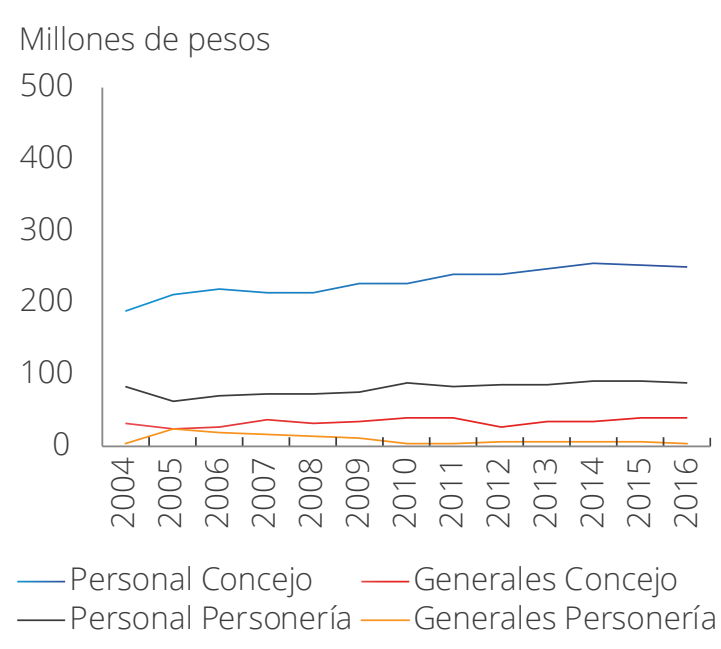

Fuente: cálculos propios a partir de los datos del DAHM.

Los gastos por concepto de Servicio de la Deuda, que son los montos destinados al pago de obligaciones (por ejemplo intereses y amortizaciones) de créditos otorgados al municipio por entidades externas, representan cerca del 3\% de los gastos totales de la administración de Santander de Quilichao. En este sentido, el servicio de la deuda es muy bajo y da margen de acción a una política fiscal activa que desde el gobierno municipal lleve al municipio por importante sendas de crecimiento económico.

En el Gráfico 14 se observa un comportamiento bastante fluctuante hasta el año 2011, donde se estabilizan los gastos al servicio de la deuda con una tendencia creciente hasta el último año estudiado, lo cual da muestra de que parte de la gestión de la administración 2012-2015 se basa en el manejo de los compromisos de la entidad, y aunque los ingresos del municipio pueden hacer frente a esta tendencia creciente de la deuda, sí es importante tener prestarle atención a largo plazo para que su tendencia no vaya a afectar las finanzas públicas del municipio.

Gráfico 14. Servicio de la Deuda (2004-2016)

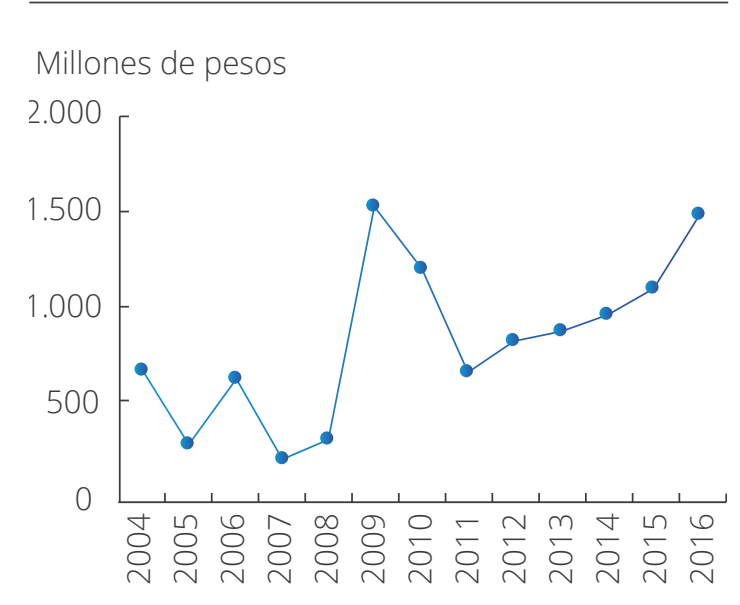

Fuente: cálculos propios a partir de los datos del DAHM.

\section{Déficit primario del municipio}

Como se explicó en la sección teórica, el déficit total o convencional equivale al exceso del gasto público respecto a sus ingresos, traduciendo esta diferencia entre las variables a la necesidad de financiamiento que la entidad deberá cubrir con nueva deuda u otras fuentes de financiamiento como la venta de activos. Excluyendo de este cálculo el pago de intereses sobre la deuda del municipio, se obtiene el déficit primario municipal $y$, en este sentido, se logra una aproximación al grado de éxito que tiene la entidad para conducir sus finanzas hacia la sostenibilidad, pues éste refleja la capacidad de sostenimiento de la política fiscal municipal (Lora y Prada, 2016). En lineamiento al marco 
teórico, a continuación se muestra el comportamiento del déficit primario de Santander de Quilichao en el periodo estudiado.

Como se logra apreciar en el Gráfico 15, los ingresos del municipio fueron superiores a sus gastos, acercándose de manera significativa solamente para el año 2012, año que coincide con el inicio del periodo del Alcalde Luis Eduardo Grijalba Muñoz, pero también con la caída del 22\% en los impuestos y $36 \%$ en ingresos no tributarios, de los cuales rubros importantes como las transferencias cayeron en un 35\% y los fondos especiales en un $67 \%$. Esto hizo que el déficit primario fuera positivo en el año 2012 (Gráfico 16), aproximadamente en mil millones de pesos.

Gráfico 15. Gastos e ingresos

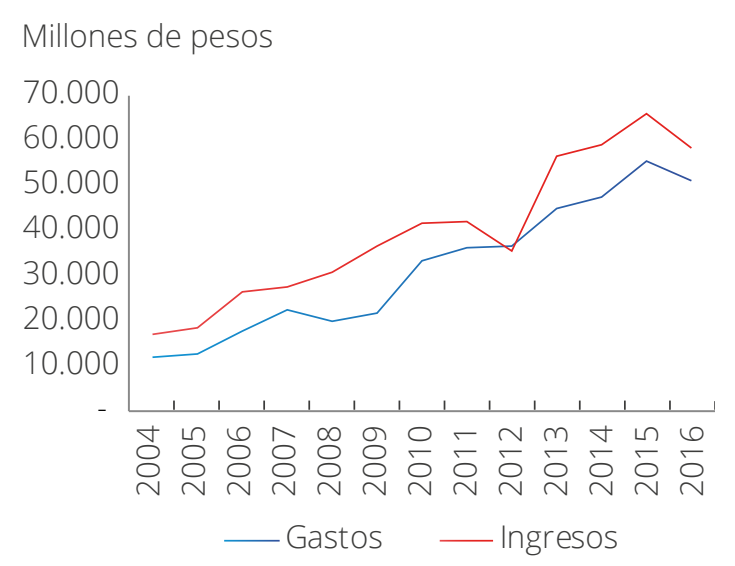

Fuente: cálculos propios a partir de los datos del DAHM.

En general, para todo el periodo 2004 - 2016 se puede observar que el municipio presentó un balance positivo entre ingresos y gastos, de manera que la política fiscal es favorable para la población en el sentido de que se han administrado bien los recursos y con un manejo responsable de las finanzas públicas, así como se pudo observar, en el direccionamiento del gasto en inversión de bienes públicos como la salud y la educación que favorecen el desarrollo local del municipio. Estos buenos resultados en materia fiscal, evidencia los efectos positivos con la puesta en marcha de la Ley 617 de 2000, cuando los municipios cambiaron su tendencia deficitaria a superávits.

Gráfico 16. Déficit Primario

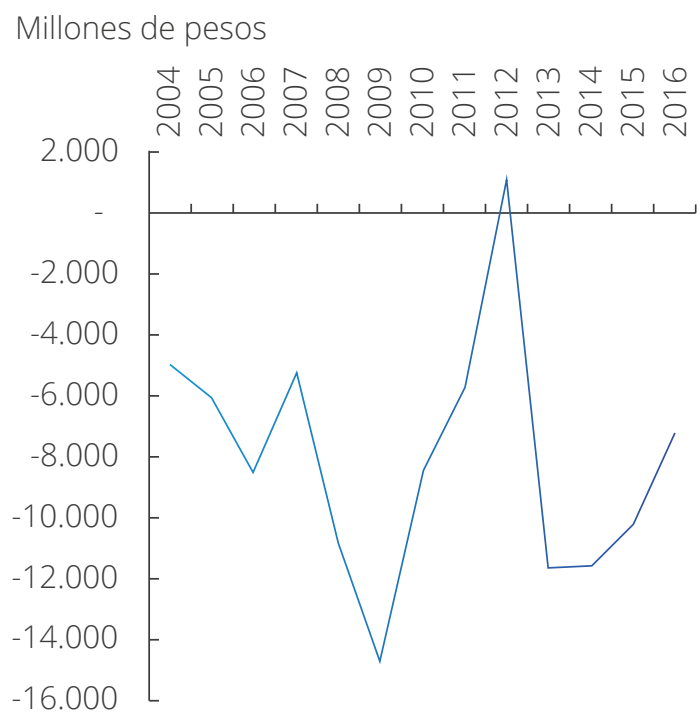

Fuente: cálculos propios a partir de los datos del DAHM.

\section{Indicadores de desempeño fiscal}

En el Gráfico 17 se observa en primer lugar el indicador de Autofinanciación del Funcionamiento, el cual mide la proporción de los recursos de libre destinación, excluyendo los recursos que por ley se destinan específicamente para inversión u otro fin, que se disponen para el pago de nómina y de gastos generales de la operación 
de la administración central del municipio. Los datos indican que en el periodo estudiado el municipio siempre estuvo por debajo del 80\%, cumpliendo con el límite establecido por la Ley 617 de 2000 para municipios de $4^{\mathrm{a}}, 5^{\mathrm{a}}$ y $6^{\text {a }}$ categoría.

Bajo estos resultados, es posible afirmar que Santander de Quilichao cuenta con un margen prudente que le permite adecuar su estructura administrativa y hacer modificaciones a su planta de personal con el fin de mejorar su gestión pública y, por consiguiente, la calidad de los servicios que presta a los quilichagüeños.

Respecto al segundo indicador, Magnitud de la Deuda, se mide la capacidad de respaldo financiero en cuanto a solvencia y sostenibilidad que tiene el municipio para adquirir deuda, en relación con los indicadores de la Ley 358 de 1997 y Ley 819 de 2003. El Gráfico 18 permite observar que la deuda total del municipio no supera su capacidad de pago ni compromete su liquidez para el pago de otros gastos, a pesar de que su tendencia ha sido creciente desde el año 2011, como se puede observar en el Gráfico 14. De esta manera, los indicadores obtenidos dan muestra de que los créditos comprometidos no exceden los recursos de los que dispone Santander de Quilichao para respaldarlos.

Por su parte el indicador de Dependencia de las Transferencias, mide la importancia que tienen las transferencias que recibe el municipio respecto al total de fuentes de financiación, reflejando el grado en el que las transferencias se vuelven recursos fundamentales para la financiación del desarrollo del municipio. Índices por más del $60 \%$ revelan que la entidad financia sus gastos especialmente con recursos de transferencias; así, lo que indican los resultados del Gráfico 19, es que el municipio de Santander de Quilichao ha financiado sus gastos tanto con recursos propios como con las transferencias que recibe de la nación, de manera casi equitativa a partir de 2009.

Gráfico 17. Autofinanciación del Funcionamiento

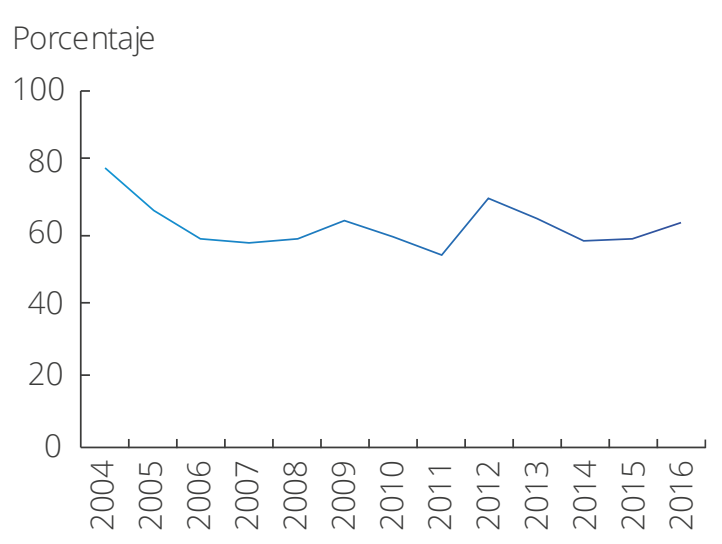

Fuente: cálculos propios a partir de los datos del DAHM.

Gráfico 18. Magnitud de la Deuda

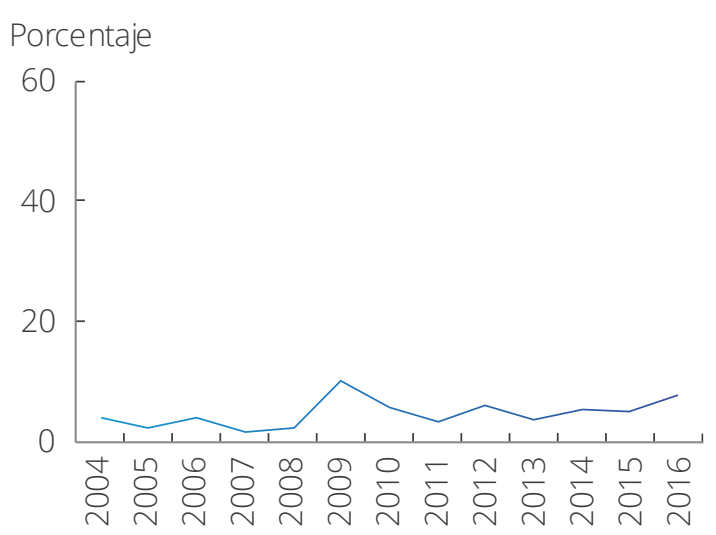

Fuente: cálculos propios a partir de los datos del DAHM. 
Bajo las afirmaciones de Zapata (2010) y Bonet et al. (2018), se puede sostener que la autonomía territorial para el municipio no generó pereza fiscal, al tener un mayor dinamismo de los ingresos corrientes que de las transferencias. Estos resultados son favorables en el sentido de que al no tener alta dependencia de las transferencias, el municipio es menos vulnerable de presentar desequilibrios económicos en su estructura financiera.

Esto mismo, en los términos de Gamarra (2013) es que, teniendo en cuenta que los municipios más grandes cuentan con un sistema económico más dinámico, reducen su dependencia de las transferencias, básicamente porque tienen capacidad mayor de generar de recursos propios y de forma más sólida; contrario a lo que pasa con los entes territoriales más pequeños, donde se vuelven más importantes las transferencias gubernamentales, hecho dado porque su estructura tributaria es más pequeña y por lo tanto se afecta la captación de recursos propios.

Respecto al Indicador de Generación de Recursos Propios, el Gráfico 20 complementa al indicador Dependencia de las Transferencias (Gráfico 19), dado que refleja el peso de los ingresos tributarios sobre el total de ingresos corrientes, reflejando el esfuerzo fiscal del municipio al comparar los impuestos que éste genera autónomamente, y mide la importancia de su gestión tributaria frente a otras fuentes externas de financiamiento del gasto corriente. En general se observa que el esfuerzo fiscal del municipio es en promedio del $40 \%$, por lo que la actividad económica del municipio no se ve influenciada en gran medida por la injerencia del gobierno municipal, al punto que en crisis económica hay margen para actuar desde la política fiscal. En cuanto a su tendencia, se observa que desde el año 2013 ha venido creciendo, pasando del 38\% al 52\%, que en general no es grave, pero sí para prestarle atención.

Gráfico 19. Dependencia de las Transferencias

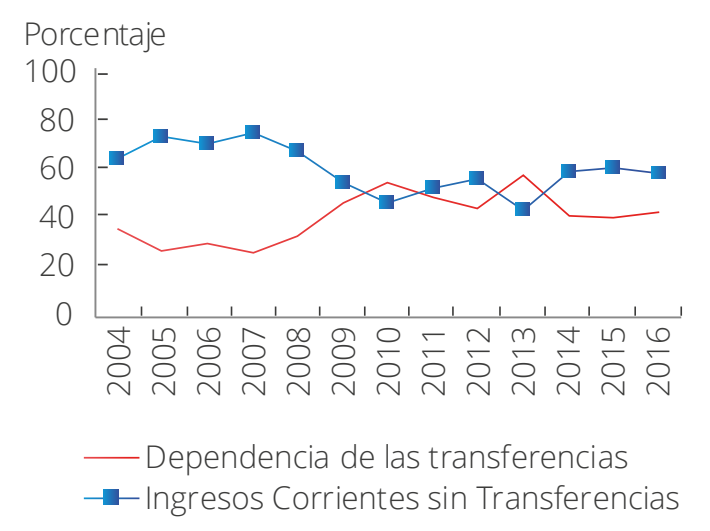

Fuente: cálculos propios a partir de los datos del DAHM.

Gráfico 20. Generación de Recursos Propios

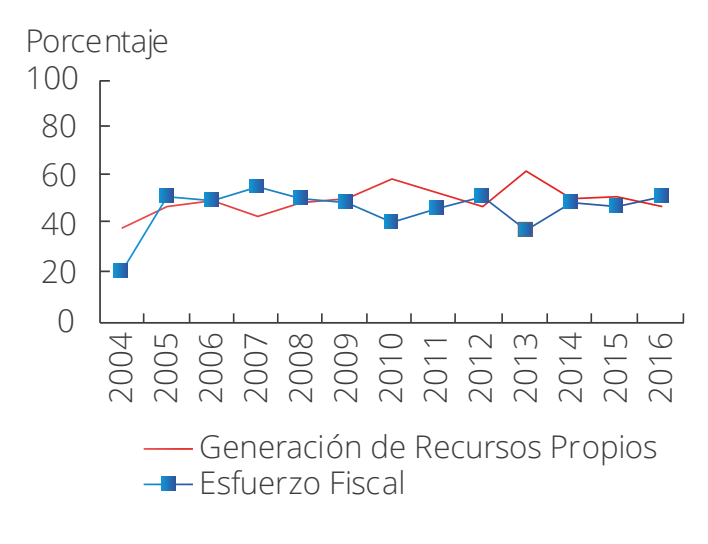

Fuente: cálculos propios a partir de los datos del DAHM.

Por lo que se refiere al indicador de Magnitud de la Inversión (Gráfico 21) 
que permite medir el grado de gasto en inversión que hace el municipio respecto al gasto total, se espera que el indicador sea mayor a 50\%. Los resultados en el Gráfico 21 muestran que en el municipio de Santander de Quilichao se destina gran parte del gasto a la inversión, en una proporción significativa y creciente. En lineamiento a las conclusiones de Zapata (2010), la mejor manera de resumir la evolución del consolidado de las finanzas de los municipios está en el incremento de los recursos totales que se destinan a la inversión y a la manera como esta se financia. En este sentido y complementado con el Gráfico 11, los gastos se enfocan mayormente en salud y educación, es decir, en capital humano que a la luz de la teoría son variables esenciales para un crecimiento económico sostenido de largo plazo (Romer, 1990; Lucas, 1988; Marín, Hernández y Burbano, 2018).

Finalmente, está el indicador de Capacidad de Ahorro que muestra el balance entre ingresos corrientes y gastos corrientes del municipio; esto es el ahorro corriente como porcentaje de los ingresos corrientes, y brinda una idea de la solvencia que tiene la administración municipal para generar excedentes propios con destino a la inversión. Como se observa en el Gráfico 22, el indicador es positivo, lo cual indica que la entidad genera ahorro, aunque desde el año 2013 tal capacidad de ahorro se ha visto afectada con tendencia decreciente.

Tal reducción podría estar indicando posibles incrementos en el déficit, lo que se traduce en la poca capacidad para generar ahorro en el municipio, pérdida de la capacidad de inversióny, consecuentemente, perturbación en el desarrollo económico y social, y en la competitividad municipal. De esta manera, aunque ciertos indicadores muestran escenarios positivos del gobierno municipal, es importante controlarlos para que hacia el largo plazo no se vean afectadas las finanzas y planes de inversión del municipio.

Gráfico 21. Magnitud de la Inversión

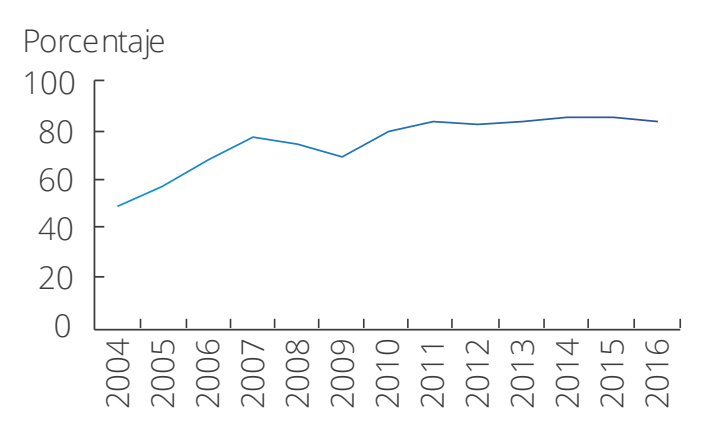

Fuente: cálculos propios a partir de los datos del DAHM.

Gráfico 22. Capacidad de Ahorro

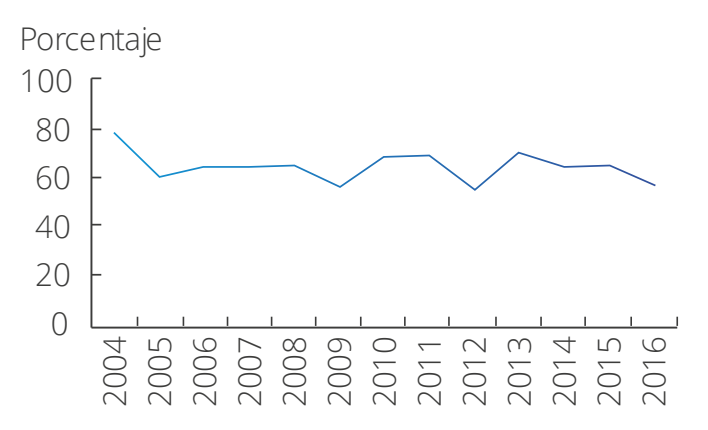

Fuente: cálculos propios a partir de los datos del DAHM.

\section{Conclusiones}

Teniendo en cuenta todo lo anterior, es posible afirmar que en el periodo 
estudiado la situación financiera del municipio ha sido sostenible y el control de gastos ha sido prudente en el tiempo, lo que también se confirma con los datos del año 2016 que publica el DNP ubicando al municipio de Santander de Quilichao en el rango de sostenible; aun así, algunos indicadores en los últimos años de estudio advierten la necesidad de que la administración preste atención a los gastos, ingresos y deuda, con el fin de seguir siendo sostenibles en el largo plazo.

Precisamente, uno de los aspectos más importantes y relevantes que destacar del manejo en la restricción presupuestaria del municipio de Santander de Quilichao, es la componente del gasto fiscal. Dentro del gasto público, los rubros que tuvieron la mayor participación fueron la salud y la educación, variables de capital humano que en diversos trabajos teóricos y empíricos han demostrado su influencia positiva y significativa sobre el crecimiento y desarrollo económicos.

Con relación a los ingresos, el municipio recibe aproximadamente lo mismo en impuesto tributarios como no tributarios, sin embargo, dentro de los impuestos tributarios recibe la mayor parte de impuestos indirectos especialmente del impuesto de industria y comercio (18\% aproximadamente de todos los ingresos), mientras que de los ingresos no tributarios, recibe el $42 \%$ de todos los ingresos de las transferencias del Estado y especialmente del Sistema General de Participaciones (41\%).

Respecto al déficit primario, se pudo observar que la evolución en general es favorable para el municipio, de manera tal que los recursos han sido bien administrados y bajo una política fiscal responsable. Estos buenos resultados evidencian los efectos positivos con la puesta en marcha de la Ley 617 de 2000, que mantuvo en el periodo estudiado en escenarios de superávit fiscal. Así mismo, se concluye que las presiones fiscales sobre la economía municipal no son mayores y que por el contrario, si se tiene en cuenta la estructura de gastos, son más bien positivas en el orden del desarrollo local.

Finalmente, con el análisis de las variables de la restricción presupuestaria fiscal y los indicadores del DNP, se puede afirmar que la autonomía territorial no generó pereza fiscal, de manera que el municipio generó mayor dinamismo a partir de los ingresos corrientes que de las transferencias. Estos resultados son favorables en el sentido de que al no tener alta dependencia de las transferencias, el municipio es menos vulnerable de presentar desequilibrios económicos en su estructura financiera.

\section{Referencias}

Alesina A., Carrasquilla, A., \& Echavarría, J. (2000). La Descentralización en Colombia. Fedesarrollo, Working Papers No. 15. Recuperado de http://hdl. handle.net/11445/824

Amieva, J. (2004). Finanzas Públicas en México. México: Editorial Porrúa, (Obra original publicada en 1848).

Barro, R. \& Lee, J. (2010). A new data set of educational attainment in the World, 1950-2010. National Bureau of Economic Research, Working Paper 
15902. Recuperado de http://www. nber.org/papers/w15902

Becker, G. (1993). Human Capital. A theoretical empirical analysis with special reference to education. New York: The University of Chicago Press, (Obra original publicada en 1964).

Bonet, J., Pérez, G. \& Montero, J. (2018). Las finanzas públicas territoriales en Colombia: dos décadas de cambios. Banco de la República, Documentos de Trabajo sobre Economía Regional y Urbana, (267). Recuperado de http:// repositorio.banrep.gov.co/handle/20.500.12134/9187

Bonet, J. y Pérez, G. (2019). Financiamiento y calidad del gasto social. En: J. Bonet \& D. Ricciuli (ed.), Casa Grande Caribe, Capítulo 5, pg. 192-231, Banco de la Republica de Colombia. Recuperado de http://repositorio.banrep.gov. co/handle/20.500.12134/9721

Blanchard, O., Amighini, A. \& Giavazzi, F, (2017). Macroeconomía. Madrid: Pearson S.A.

Cadena, X. (2002). ¿La descentralización empereza? Efecto de las transferencias sobre los ingresos tributarios municipales en Colombia. Desarrollo y Sociedad, (50), 67-108. Recuperado de https://doi.org/10.13043/dys.50.2

Conchas, E. A. (2001). Finanzas públicas de México. México: Instituto Politécnico Nacional, (Obra original publicada en 1992).

Delgado, S, Cárdenas, J., \& Fuentes, H. (2020). Los municipios de sexta categoría de Colombia(2000-2016): entre la autonomía y la dependencia. Apuntes Del Cenes, 39(69). https:// doi.org/10.19053/01203053.v39. n69.2020.10172

Departamento Nacional de Planeación -DNP- (2010). Desempeño fiscal de los departamentos y municipios 2010. Bogotá: DNP. Recuperado de https:// colaboracion.dnp.gov.co/CDT/Desarrollo\%20Territorial/Desempe\%C3\%B10\%20Fiscal\%202010.pdf

Fergusson, L. \& Suárez, G. (2010). Política Fiscal: Un enfoque de tributación óptima. Bogotá: Ediciones Uniandes.

Giraldo, C. (2009). Finanzas Públicas en América latina. La Economía Política. Bogotá: Ediciones Desde Abajo, (Obra original publicada en 2001).

Gamarra, S. (2013). Desempeño fiscal de los municipios que conforman la propuesta de creación del nuevo departamento de la depresión momposina (2000-2010) (Tesis de pregrado). Recuperado de http://190.242.62.234:8080/jspui/ handle/11227/1245

Hernández, A. \& Barreto, L. (2018). Descentralización y finanzas territoriales. Cuadernos de Fedesarrollo, (59). Recuperado de https://www.fedesarrollo.org.co/sites/default/files/CDF_ No_59_Marzo_2018.pdf

Junguito, R. \& Rincón, H. (2004). La Política fiscal en el siglo XX en Colombia. Banco de la República, Borradores de economía, (318). Recuperado de http:// www.banrep.gov.co/sites/default/files/publicaciones/pdfs/borra318.pdf

López, N., López, M. \& Mesa, R. (2014). Finanzas públicas y desarrollo local. El caso de los Municipios del departamento de Antioquia; Colombia (20012011). Perfil de Coyuntura Económica, (23), 57-79.

Lora, E. \& Prada, S. (2016). Técnicas de Medición Económica, Metodología y Aplicaciones en Colombia. Cali: Universidad Icesi. Recuperado de http:// repository.icesi.edu.co/biblioteca_digital/handle/10906/80745 
Lozano, I. (1999). Las transferencias intergubernamentales y el gasto local en Colombia. Revista de Economía del Rosario, 2(1), 141-160.

Lucas, R. (1988). On the mechanics of economic development. Journal of monetary economics, 22(1), 3-42.

Marín, M., Hernández, E. \& Burbano, E. (2018). Impactos del capital humano en las organizaciones empresariales y en los individuos. En Ponencia en el Encuentro Internacional de Investigadores en Administración 2018, Universidad del Valle, Santiago de Cali, Colombia. Recuperado de https:// www.academia.edu/38441141/Impactos_del_Capital_Humano_en_las_Organizaciones_Empresariales_y_en_ los_Individuos

Oates, W. (1999). An essay on fiscal federalism. Journal of Economic Literature, 37(3), 1120-1149.

Ocampo, J. (1997). Una Evaluación de la Situación Fiscal Colombiana. Coyuntura económica, 27(2), 89-121. Recuperado de http://hdl.handle. net/11445/2162

Ospina, P. \& Gutiérrez, C. (1996). Desempeño financiero de las entidades municipales 1993-1995. Coyuntura Económica, 26(1), 77-94. Recuperado de http://hdl.handle.net/11445/2180

Ray, D. (2002). Economía del Desarrollo. Barcelona: Antoni Bosch Editor, (Obra original publicada en 1998).
Romer, P. (1990). Endogenous Technical Change. Journal of Political Economy, 98(5), S71-S102.

Sánchez, F., Gutiérrez, C. \& Parra, J. (1994). Transferencias intergubernamentales y comportamiento fiscal de los entes territoriales. Una aproximación econométrica. Coyuntura Económica, 24(2), 89-110. Recuperado de http://hdl.handle.net/11445/2250

Tanzi, V. \& H. Zee (1997). Fiscal Policy and Long-Run Growth. Staff papers IMF, 44(2), 179-209.

Tanzi, V. (2000). El papel del Estado y la calidad del sector público. Revista de la CEPAL, (71), 7-22. Recuperado de https://repositorio.cepal.org/bitstream/ handle/11362/12207/1/071007022_ es.pdf

Tiebout, C. M. (1956). A pure theory of local expenditures. Journal of political economy, 64(5), 416-424.

Weil, D. (2006). Crecimiento Económico. Madrid: Pearson Educación.

Zapata, J. (2010). Las finanzas territoriales en Colombia. Fedesarrollo y Corporación Andina de Fomento -CAF-, Documento de Trabajo, Recuperado de https://www.caf.com/media/3782/ FinanzasTerritoriales.pdf 